\title{
Influence of Different Annealing Atmosphere Nature on the Properties of Nanoparticles CdS Thin Films Synthesized By Chemical Bath Method.
}

M. MELOUKI ( $\nabla$ melouki.mohamed@gmail.com )

University of Sciences and technology https://orcid.org/0000-0002-7169-5730

\section{Y. LARBAH}

(CRNA) Nuclear Research Centre of Algiers
A. DJELLOUL

Centre de Recherche en Technologie des Semi-Conducteurs Pour l'Energétique (CRTSE)

\section{ADNANE}

University of Sciences and technology

\section{Research Article}

Keywords: CdS, CBD, annealing atmosphere nature, microstructure and optical properties.

Posted Date: July 20th, 2021

DOI: https://doi.org/10.21203/rs.3.rs-728279/v1

License: (c) (i) This work is licensed under a Creative Commons Attribution 4.0 International License. Read Full License 


\title{
Influence of different annealing atmosphere nature on the properties of nanoparticles CdS thin films synthesized by chemical bath method.
}

\author{
M. MELOUKI ${ }^{1 *}$ Y. LARBAH ${ }^{2}$, A. DJELLOUL ${ }^{3}$ and M. ADNANE ${ }^{1}$ \\ ${ }^{1}$ University of Sciences and technology, MOHAMED BOUDIAF; El Mnaouar, BP 1505, Bir El Djir 31000 ORAN Algeria. \\ ${ }^{2}$ (CRNA) Nuclear Research Centre of Algiers, Algeria. \\ ${ }^{3}$ Centre de Recherche en Technologie des Semi-Conducteurs Pour l'Energétique (CRTSE), 02 Bd Frantz Fanon, BP 140, 7 Merveilles, \\ Alger, Algérie. \\ "Email : melouki.mohamed@gmail.com; mohamed.melouki@uni v-usto.dz
}

\begin{abstract}
:
The Cadmium sulfide $(\mathrm{CdS})$ is the most advantageous material for the manufacture of the elaborate solar cells in thin layers, the study that we present, will relate to the elaborated and the characterization of $\mathrm{CdS}$ thin film deposited on glass substrates by chemical bath deposition (CBD) method. This study will help us to know if the annealing atmosphere nature affects the deposition of thin films of CdS. The X-ray diffraction (XRD) analysis reveals that the structures of pure thin films are Hexagonal and polycrystalline with preferential orientation (002). The scanning electron microscopy (SEM) measurements showed that the surface morphology homogeneous and uniform. The energy dispersive X-ray analysis (EDAX) studies confirmed that the films are nearly stoichiometric. The transmittance in the visible region (200-800 nm) is high of $60 \%$, and band gap values oscillated between 2.36 and $2.47 \mathrm{eV}$ for al thin films.
\end{abstract}

Keywords: CdS, CBD, annealing atmosphere nature, microstructure and optical properties.

\section{1- Introduction:}

Cadmium sulfide $(\mathrm{CdS})$ is considered to be one of the most promising and utilized materials as window layer in different type of hetero-junction solar cells [1,2]. It is an n-type semiconductor [3] that belongs to the chalcogenide family, which is characterized by a high absorption coefficient and a wide band gap energy $\mathrm{E}_{\mathrm{g}}=2.40 \mathrm{eV}$ [4]. These last years the $\mathrm{CdS}$ thin films took a large part in the work of solar cells based on thin films. CdS thin films can be deposited by serval method as RF magnetron sputtering [5], chemical vapour deposition [6], sol-gel [7], spray pyrolysis [8] and chemical bath deposition (CBD) $[9,10]$. The last method has increased interest in the preparation of thin films, due to certain advantages, because it is simple, inexpensive and allows to deposit thin films with large surface. 
In this study, thin films of Cadmium Sulfide (CdS) deposited by the chemical bath method (CBD), the effect of different annealing atmosphere nature on the microstructure and optical properties of the CdS films are discussed.

\section{2- Experimental:}

The first step in this work the preparation of the chemical bath, the precursors used to deposit our thin films $\mathrm{CdS}$ and as a follow; the product used as a source of cadmium is cadmium chloride $\mathrm{CdCl}_{2}$, mixed with Thiourea $\left[\mathrm{SC}\left(\mathrm{NH}_{2}\right)_{2}\right]$ were prepared using distilled water as source of sulfur, mixed with an complexing agent $\mathrm{NH}_{4} \mathrm{Cl}$. The bath temperature was regulated with an IKA ETS-D6 regulator, the bath temperature is $60^{\circ} \mathrm{C}$ and the deposition time was $60 \mathrm{~min}$, we used this condition after many study of condition of deposition [10-14].

The CdS film reflects the electron. Annealing films of $\mathrm{CdS}$ thereby at $500^{\circ} \mathrm{C}$ under nitrogen for 1 hour. These conditions of deposit have been chosen based on the study carried out by The choice of annealing under nitrogen is due to the sulfur oxide formation if one makes the annealing under oxygen. This study will help us to know if the annealing atmosphere nature affects the deposition of thin films of CdS.

The structural proprieties of $\mathrm{CdS}$ thin films were carried out using X-Ray diffractometer (BRUKER AXS D5000 X-ray Diffractometer), with $\mathrm{Cu} \mathrm{K} \alpha\left(\lambda=1,54056 \mathrm{~A}^{\circ}\right)$ angel scanning $2 \theta$. The study optical have been performed using UV-Vis spectrophotometer (Helios gamma spectrophotometer) working in the range 200-800 to study the transmittance and electrical gap energy. The surface morphology was studied using scanning electron microscopy (JOEL JSM 6360).

The reaction mechanism of $\mathrm{CdS}$ nanoparticles:

For obtaining homogeneous thin films reaction must be rapid, the reaction rate can adjust it according to the ammonia concentration, the process of deposition of thin films as following:

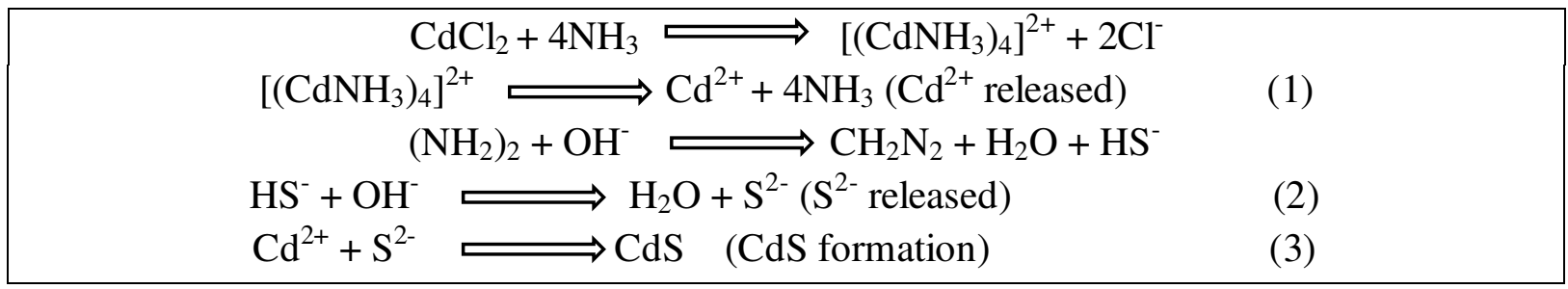

\section{1- Results and discussion:}

\section{3-1 Structural Properties:}


Figure 1 shows the X-ray diffraction diagrams of $\mathrm{CdS}$ annealing under nitrogen and oxygen, were recorded in $2 \theta$ intervals from $20^{\circ}$ up to $70^{\circ}$ with the step $0.1^{\circ}$. The diffractogram indicates the presence of the phase $\mathrm{CdS}$ compound after annealing treatment under nitrogen. As seen, it is clear that the film of $\mathrm{CdS}$ are polycrystalline the all peaks of $\mathrm{CdS}$ is detected at $2 \theta=24.90,26.85,28.65$ which can be assigned to the (010), (002), (011) respectively from (JCPDS - 98-015-4188). The preferred orientation lies along the (011) plane, the resulted XRD confirms the absence of cadmium oxide. Figure 1-b shows the XRD diffractogram of film of $\mathrm{CdS}$ annealing under oxygen we note appearance of the new peaks corresponding to the $\mathrm{CdO}$ oxide at $2 \theta=33.80 \mathrm{~nm}$ which correspond to the (200) plan from JCPDS 00-039-1221. The diffractograms indicate that the phase is hexagonal CdS. The X-ray diffraction spectra were used to determine the grain size " $\mathrm{D}$ " is calculated using the DebyeScherrer formula (1).

$$
D=\frac{k \lambda}{\beta \cos \theta}
$$

Where $\mathrm{K}$ is the Scherrer constant value corresponding to the quality factor of the apparatus measured with a reference single crystal, $\lambda$ is the wavelength of the X-ray used; $\beta$ b is the full width at half maximum of the peak and $\theta$ is the Bragg angle.

The crystallite sizes of the CdS film after different annealing values are also given in table 1 .

Table 1 shows the crystallite sizes of the CdS film after annealing under nitrogen and oxygen. The size of the crystallites varies between $35 \mathrm{~nm}$ of CdS film after annealing under nitrogen. The size of crystallite sizes of CdS varies between $30 \mathrm{~nm}$ of the $\mathrm{CdS}$ and $\mathrm{D}_{\text {moy }}=30 \mathrm{~nm}$ of the $\mathrm{CdO}$ after annealing oxygen, we find that the type of annealing influences the size of the crystals. The crystallographic study shows that the size of the crystallites does not change as a function of condition of annealing. Earlier literature Bilgin et al. [15] and Barote et al. [16] have showed similar results.

\section{3-2 Morphological and Composition:}

Figures 2-a, b shows SEM images of the CdS film deposited on a glass substrate annealing under nitrogen and oxygen .there are no fissures on the film, which means that the CBD deposit method provides us with homogeneous and uniform thin film. The CdS grain size increase from 20 to $45 \mathrm{~nm}$. The CdS film annealing under oxygen presents the particle of 
$\mathrm{CdO}$ oxide and botfly uniform on thin film. This result is in agreement with the X-ray diffraction studies.

The grains interacted with each other and agglomerated, the thickness of CdS film is approximately $80 \mathrm{~nm}$. This result is in agreement with A. Djelloul and Be Xuan Hop [17,18]. The film thickness of $\mathrm{CdS}$ films grown at $500^{\circ} \mathrm{C}$ annealing under oxygen was estimated using cross-sectional SEM images shown in figure2c. From these images, the measured film thickness was approximately $100 \mathrm{~nm}$ for $\mathrm{CdS}$ thin film, the volumes and the surfaces of these layers were uniform and dense. Compositional studies of annealed sample shown in Fig. 3 (d); show that the sample has stoichiometric growth. The EDAX technique is used to determine quantitative composition of $\mathrm{CdS}$ films deposited on glass substrate. It is clearly seen that only the peaks of $\mathrm{Cd}$ and $\mathrm{S}$ are observed, along with significant Silicon from the glass substrate. This result corroborates the one obtained from XRD.

\section{3-3 Optical Properties:}

Figure 3 shows the optical transmission spectrum (T) of thin film of CdS on glass substrate on the $\mathrm{UV}-\mathrm{V}$ is, were measured in $200-800 \mathrm{~nm}$ range. We note that the transmittance changes as a function of annealing atmosphere nature, the transmittance of the films varies between 55$60 \%$ in the visible region this results is compared to many published results [19]. This study shows that the nature of the atmosphere influences the transmittance of the film. The optical energy band gap of the films presents in fig.3-b.c.d. The band gap values were in the order of $2,40 \mathrm{eV}$ for before annealing and $2.36 \mathrm{eV}, 2.47 \mathrm{eV}$ to after annealing in $\mathrm{N}_{2}$ and after annealing in $\mathrm{O}_{2}$. These values are in good agreement with $\mathrm{CdS}$ band gap values reported by other authors [20-21].

\section{4- Conclusion :}

In summary, the influence of different annealing atmosphere nature on the microstructure and optical properties of $\mathrm{CdS}$ thin films is presented. The $\mathrm{CdS}$ has been prepared using chemical bath deposition (CBD) on glass substrate. The CdS thin films show

polycrystalline hexagonal structure, the preferred orientation lies along the (011) plane. The surface morphological analysis that the micrograph revealed a nanoparticle nature and the deposited films were found to be homogeneous, The EDX suggests the stoichiometry of the films. The optical properties depend on the atmosphere nature, it can be concluded that after a heat treatment at $500^{\circ} \mathrm{C}, 60$ minutes under a nitrogen sweep, a CdS film formed by $\mathrm{CBD}$ without the presence of $\mathrm{CdO}$ and contains some carbonaceous impurities. 


\section{ACKNOWLEDGEMENTS}

The authors would like to thank General Direction for Scientific Research and Technological Development (DGRSDT).

\section{References:}

[1] S. T. Lakshmikvmar, Sol. Energy Mater. Sol. Cells 32, 7 (1994).

[2] M. Contreras, M. Romero, B. To, F. Hasoon, R. Noufi, S. Ward, K. Ramanathan, Thin Solid Films 403/404 (2002) 204.

[3] H. Zhang, X. Ma, D. Yang, Mater. Lett. 58 (2003) 5.

[4] S. Shijori, T. Hirai, I. Komosawa, J. Chem. Soc. Chem. commun 439 (1998)..

[5] M.A. Islam, F. Haque, K.S. Rahman, N. Dhar, M.S. Hossain, Y. Sulaiman, N. Amin, Optik- International Journal for Light and Electron Optics, 126 (2015) 3177-3180.

[6] D. Barreca, A. Gasparotto,C. Maragno, and E. Tondello, J. Electrochem. Soc. 151 (2004) 428-435.

[7] M. Thambidurai, S. Agilan, N. Muthukumarasamy, N. Murugan, R. Balasundaraprabhu, Int. J. Nanotechnol. Appl. 3 (2009) 29.

[8] Y. Larbah, B. Rahal, M. Adnane, Journal of Optoelectronics and Advanced Materials 22, 518-522 (2020).

[9] J. Li, Ceramics International, 41 (2015) S376-S380

[10] A. Rmili, F. Ouachtari, A. Bouaoud, A. Louardi, T. Chtouki, B. Elidrissi,H. Erguig, Journal of Alloys and Compounds, 557 (2013) 53-59.

[11] F Ouachtari, A Rmili, S Elidrissi, A Bouaoud, H Erguig, P Elies, Journal of Modern Physics, 2011, 2, 1073-1082.

[12] Poulomi Roy, Suneel Kumar Srivastava, Materials Chemistry and Physics 95 (2006) 235-241.

[13] Fangyang Liu, Yanqing Lai, Jun Liu, Bo Wang, Sanshuang Kuang, Zhian Zhang, Jie Li, Yexiang Liu , Journal of Alloys and Compounds 493 (2010) 305-308 .

[14] O.S. Heavens, Optical properties of Thin Solid Films, Dover Publications, INC., New York, 1991, ISBN 0-486-66924-6

[15] Bilgin V, Kose S, Atay F and Akyuz I 2005 Mater. Chem. Phys. 94103.

[16] Barote M A, Yadav A A and Masumdar E U 2011 Physica B 4061865.

[17] A. Djelloul, M. Adnane, Y. Larbah, M. Zerdali, C. Zegadi, A. Messaoud J. NANOELECTRON. PHYS. 8, 02005 (2016)

[18] Be Xuan Hop, Ha Van Trinh, Khuc Quang Dat, Phung Quoc BaoVNU Journal of Science, Mathematics - Physics 24 (2008) 119-123.

[19]: Hani Khallaf, Isaiah O. Oladeji, Guangyu Chai, Lee Chow, Thin Solid Films 516 (2008) 7306-7312.

[20] C.Doroody, K.S.Rahman, H.N.Rosly ,M.N.Harif M.Isah ,Y.B.Kar, S.K.Tiong ,N.Amin,; Materials Science in Semiconductor Processing, Volume 133, October 2021, 105935.

[21] M.V.Malashchonak, E.A.Streltsov A.V.Mazanik A.I.Kulak S.K.Poznyak O.L.Stroyuk S.Ya.Kuchmiy P.I.Gaiduk. Thin Solid Films Volume 589, 31 August 2015, Pages 145-152. 

Figures

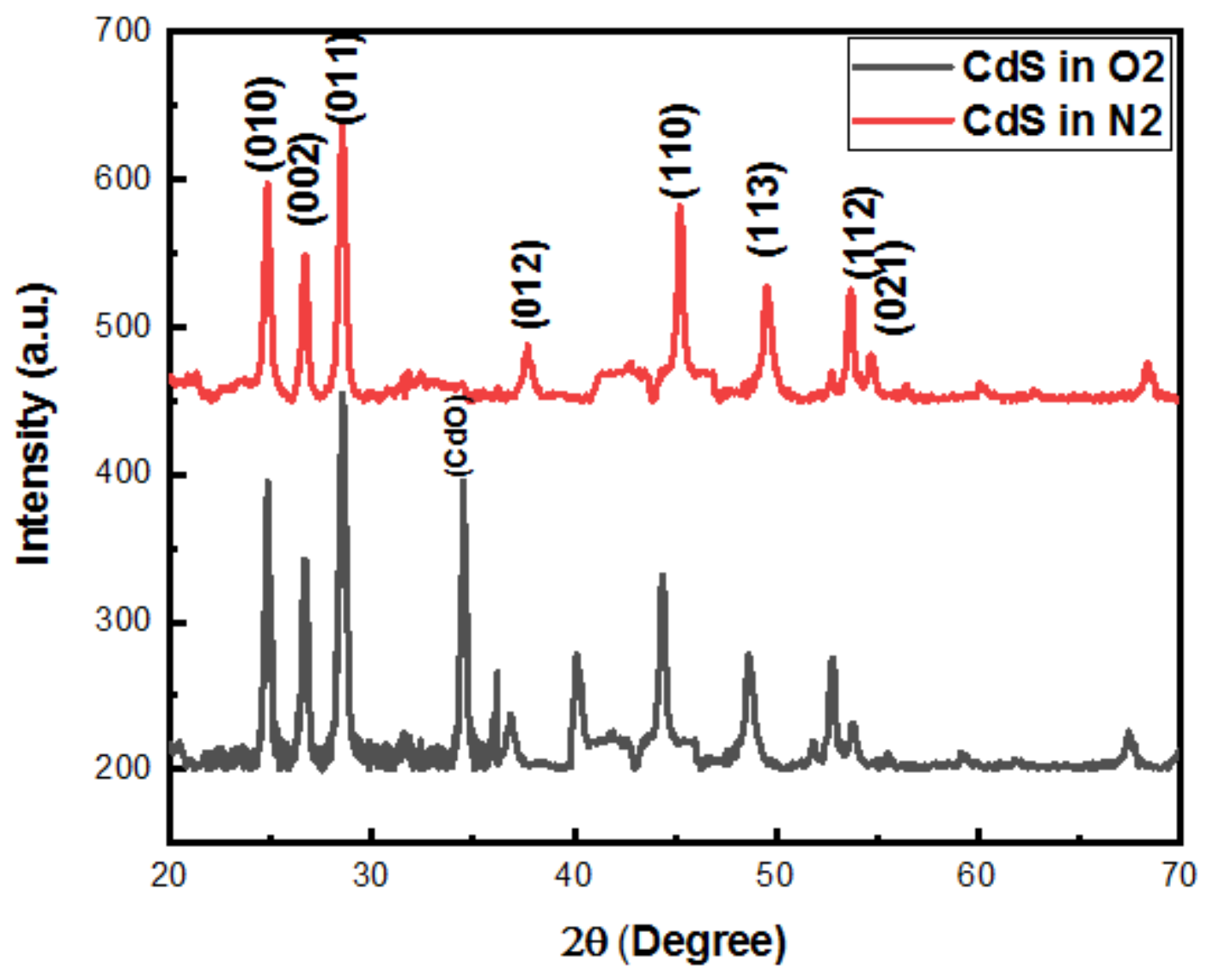

Figure 1

XRD patterns of CdS thin films annealed at different atmospheres. 

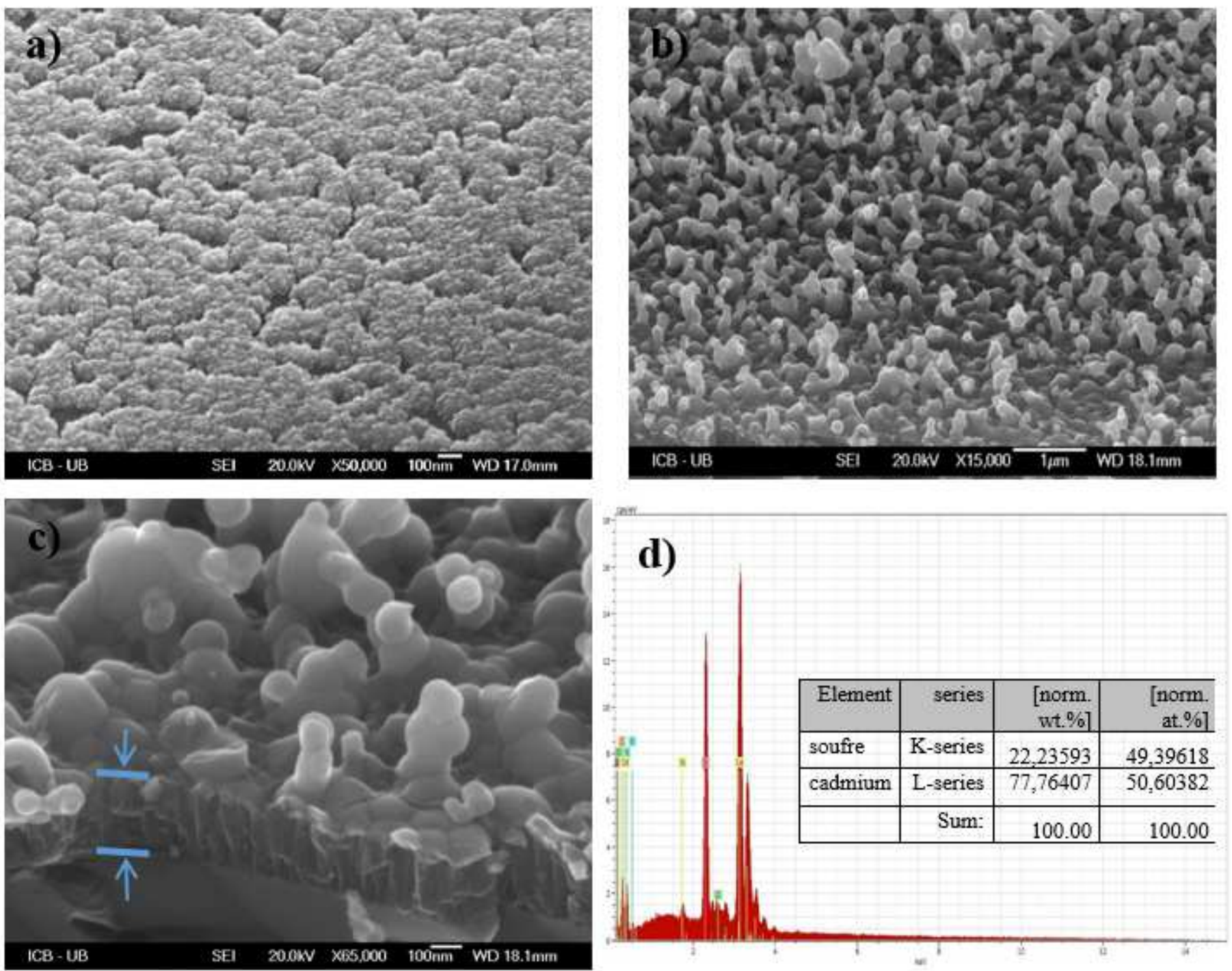

\section{Figure 2}

SEM micrographs of CdS thin films annealing under: a) nitrogen and b) oxygen, c) Cross-sectional SEM image of CdS film grown at $500^{\circ} \mathrm{C}$ annealing under oxygen, d) EDAX spectrum of annealed CdS thin film. 

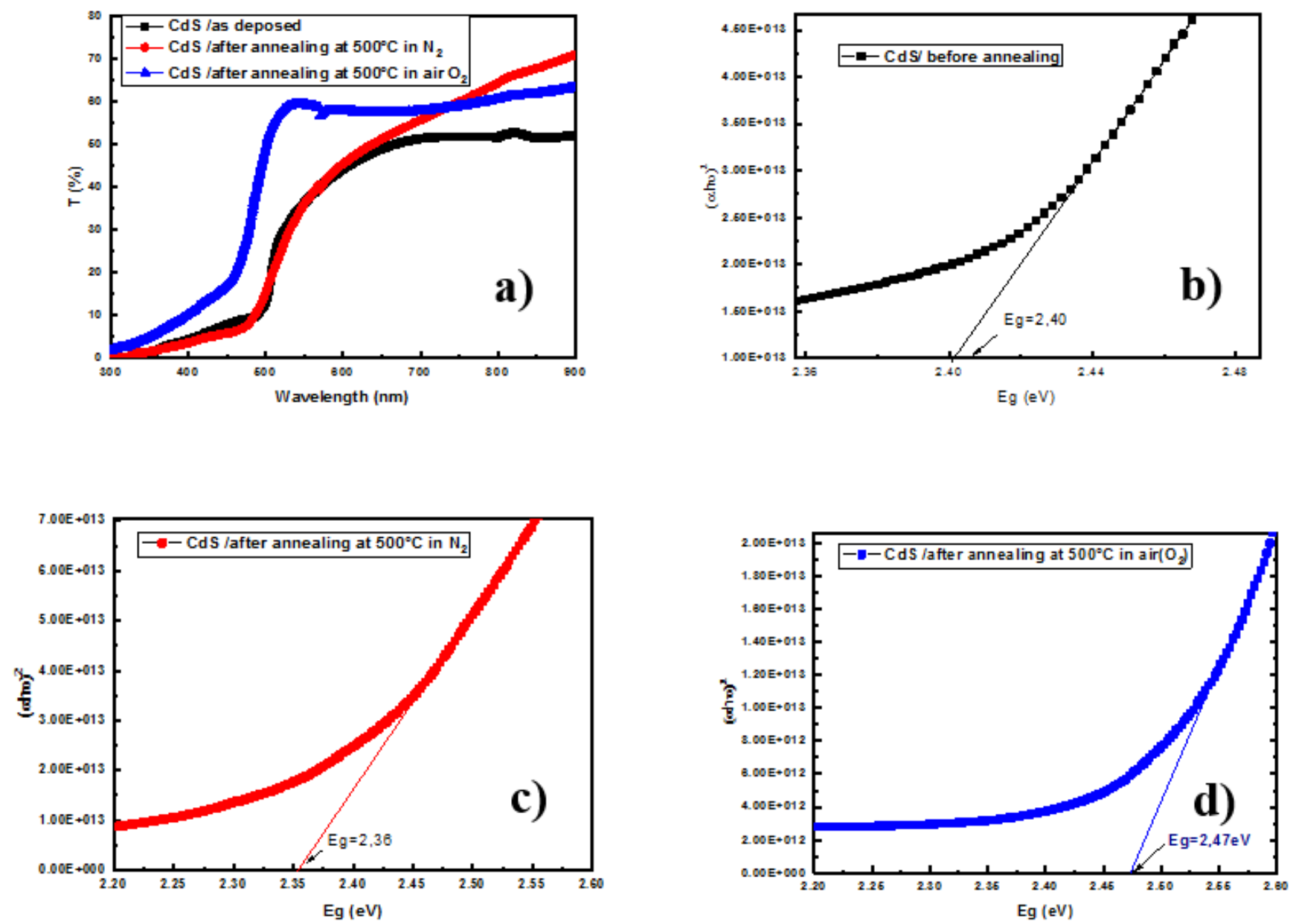

Figure 3

Optical transmittance spectra of CdS thin films and Variation of (ah囚)2 with photon energy (Eg) of CBD CdS films. 